\title{
Arkeolojik Alanlarda Jeofizik Prospeksiyon: Pisidia Mallos Örneği
}

\author{
Çağlayan BALKAYA ${ }^{1,2 *}$, Açelya SEVER ${ }^{3}$, Olcay ÇAKMAK ${ }^{2}$, Fikret ÖZCAN ${ }^{4}$

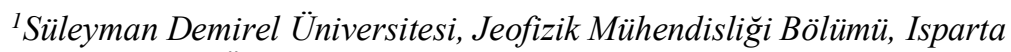 \\ ${ }^{2}$ Süleyman Demirel Üniversitesi, Deprem ve Jeoteknik Araştırma Merkezi, Isparta \\ ${ }^{3}$ Süleyman Demirel Üniversitesi, Fen Bilimleri Enstitüsü, Isparta \\ ${ }^{4}$ Süleyman Demirel Üniversitesi, Arkeoloji Bölümü, Isparta \\ (ORCID: 0000-0002-0191-8564) (ORCID: 0000-0002-9955-3806) \\ (ORCID: 0000-0003-4282-4481) (ORCID: 0000-0002-0643-3881)
}

\begin{abstract}
Öz
Sarridris kasabasının (Eğirdir, Isparta) 2 km kuzeydoğusunda konumlanan Pisidia Mallos antik kenti Hellenistik Dönem'de kurulan bir kenttir. Kentin agora alanında arkeolojik alanlarda yaygın olarak kullanılan tahribatsız yer radarı/jeoradar yöntemiyle olası yapı kalıntılarının görüntülenmesi amacıyla bir arkeojeofizik çalışma gerçekleştirilmiştir. Yer radarı çalışması, 223 profil boyunca $500 \mathrm{MHz}$ frekanslı korumalı bir anten kullanılarak gerçekleştirilmiş ve elde edilen veri kümeleri bir dizi temel veri işlem adımlarıyla değerlendirilmiştir. Veri değerlendirme bulguları, yeraltında düzenli geometriler sunan insan yapımı arkeolojik kalıntılara atfedilebilecek dört düzenli yapının varlığını göstermektedir. Bunlar arasında en umut verici belirtinin elde edildiği alanda bir elektrik özdirenç tomografi çalışması önerilmektedir. Her iki çalı̧̧madan elde edilecek bulguların birlikte değerlendirilmesiyle agora alanında bir arkeolojik deneme açmasının gerçekleştirilmesi uygun olacaktır. Mallos Antik Kenti'nde yürütülen arkeolojik çalışmaların yüzey araştırmaları olarak devam ettiği düşünüldüğünde elde edilecek sonuçlar ileri dönemlerdeki kazı planlaması çalışmalarına rehberlik edecektir.
\end{abstract}

Anahtar kelimeler: Pisidia Mallos, yer radarı, arkeoloji, jeofizik.

\section{Geophysical Prospection at the Archaeological Sites: Pisidia Mallos Example}

\begin{abstract}
Pisidia Mallos Ancient City, which is located $2 \mathrm{~km}$ northeast of Sarıidris Town (Eğirdir, Isparta) is a city established during the Hellenistic Period. An archaeo-geophysical survey has been carried out in the agora area of the city to visualize possible structure remains by using the non-destructive ground-penetrating radar (GPR) method, which is widely used in archaeological areas. GPR study has been conducted using a shielded antenna with a center frequency of $500 \mathrm{MHz}$ along 223 profiles, and data sets obtained have been evaluated with a series of basic data processing steps. Data evaluation findings indicate the presence of various regular structures that can be attributed to man-made archaeological remains displaying regular geometries in the subsurface. Of them, an electrical resistivity tomography study is recommended in the area where the most promising anomaly is obtained. It will be appropriate to carry out an archaeological trial trench in the agora area by evaluating the findings obtained from both studies. Considering that the archaeological works carried out in the ancient city of Mallos continue as surface surveys, the results obtained will guide the excavation planning in the future.
\end{abstract}

Keywords: Pisidia Mallos, Ground-penetrating radar, archaeology, geophysics.

\section{Giriș}

Arkeolojik alanlarda jeofizik prospeksiyon çalışmaları, klasik kazı teknikleriyle gerçekleştirilen çalışmalara göre çok daha kısa bir sürede, daha az maliyetle ve aynı zamanda yeraltındaki yapıya zarar vermeden gerçekleştirilmektedir. Bu nedenle tahribatsız jeofizik yöntemler, yoğun bir emek, sabır ve zaman gerektiren ulusal/uluslararası arkeolojik kazılarda son zamanlarda yaygin olarak

"Sorumlu yazar: caglayanbalkaya@sdu.edu.tr

Geliş Tarihi: 26.09.2019, Kabul Tarihi: 12.02.2020 
uygulanmaktadır. Bunlar arasında; manyetik, elektrik özdirenç ve yer radarı (ground-penetrating radar, GPR) en s1k uygulanan ve en verimli jeofizik yöntemlerdir.

Manyetik prospeksiyon arkeolojik bir alanda ilk kez 1956 yılında uygulanmış [1, 2] ve bu zamandan günümüze değin geçen sürede geniş arkeolojik alanlarda gömülü yapı ve kalıntılarının belirlenmesi ve haritalanmasında en önemli yöntemlerden biri haline gelmiştir [3]. Elektrik özdirenç yönteminin arkeolojik prospeksiyonda ilk uygulamaları ise 1946 yılında İngiltere'de Aitken tarafindan gerçekleştirilirken Lundberg, 1947 yılında Meksika'da Tepexpan Adamı'nın keşfinde bu yöntemi uygulamıştır [4]. Yer radarı yönteminin arkeolojide ilk uygulamasıysa 1970'lere dayanmaktadır [5]. Chaco Canyon (New Mexico)'da Vickers ve Dolphin [6] tarafindan gerçekleştirilen ve $1 \mathrm{~m}$ derinliğe kadar gömülü duvarların görüntülendiği çalışma, yöntemin ilk uygulamalarından biridir [7]. Ülkemizde ise arkeoloji jeofiziği uygulamaları ilk olarak 1960'larda Keban kurtarma kazıları ile başlarken, Yaramancı [8], ODTÜ destekli kurtarma kazı çalışmalarında Tepecik ve Norşun Höyüğü ile Ağın Kalesinde elektrik özdirenç yöntemiyle çalışmalar gerçekleştirmiştir [9].

Son yıllarda, genel olarak, bu üç yöntemin kullanıldığı jeofizik çalışmaların yüzeye yakın arkeolojik yapıların yeri, derinliği ve uzanımlarının araştırılmasında kullanımı oldukça yaygınlaşmıştır. Sardis [10], Satala [11], Zeugma [12], Smyrna Höyük [13, 14], Parion, [15, 16], Dedemezarı Nekropolü [17, 18], Amorium [19], Pisidia Antioch [20], Side [21] ve Baris [22] arkeolojik alanlarında gerçekleştirilen çalışmalar ülkemizden örnekler olarak verilebilir.

Bu çalışmada; Isparta ili, Eğirdir ilçesi, Sariidris kasabası sınırları içerisinde yer alan Pisidia Mallos Antik Kenti'nin agora alanında arkeolojik yapı kalıntılarının belirlenmesi amacıyla gerçekleştirilen bir yer radarı çalışmasının sonuçları sunulmaktadır. Kentteki ilk arkeoloji jeofiziği çalışması, Isparta Müzesi iş birliği ile 1996 yılında manyetik yöntem uygulamasıyla gerçekleştirilmiştir [23]. Yer radarı çalışması, $500 \mathrm{MHz}$ merkez frekanslı bir kapalı anten sistemiyle yaklaşık $110 \mathrm{~m} \times 25$ m büyüklügünde ve kent agorasının bir bölümünü kapsayan bir alanda gerçekleştirilmiştir. Yaklaşık DB doğrultulu 223 profil üzerinde ve toplamda 4745 m uzunluğunda toplanan veri kümeleri bir dizi temel veri-işlem tekniği uygulanarak değerlendirilmiştir. Elde edilen sonuçların görselleştirilmesiyle araştırma alanında düzenli geometriler sunan ve antropolojik yapı kalıntılarının izleri olabilecek bulgular belirlenmiştir. Bunlar arasında en dikkat çekici olan belirti, alanın 35-46 metreleri arasında elde edilmiştir. Çalışma alanının bu bölümünde bir elektrik özdirenç tomografi çalışması önerilmiştir. Böylece, her iki yöntemden elde edilen bulgular ışığında gerçekleştirilecek arkeolojik deneme açmalarının kaçak kazıların yoğun gerçekleştiği bu alanı aydınlatacağı düşünülmektedir.

\section{Materyal ve Metot}

\subsection{Mallos Antik Kenti}

Mallos Antik Kenti, Isparta ili, Saridris kasabası'nın kuş uçuşu 2 km kuzeydoğusunda ve Eğirdir Gölüne $18 \mathrm{~km}$ uzaklıkta konumlanmaktadır (Şekil 1). Kent, savaş kaygıları nedeniyle savunmaya yönelik olarak K-G doğrultusunda uzanan bir tepe üzerine kurulmuştur. Doğusunda Göynücek Yaylas1, güneydoğusunda Erenler ve İkiztepe Dağları, batısında Eğirdir Gölü, kuzeyinde Kaz Deresi ve Göynücek Deresi ile yakın çevresinde Eleksi Tepesi bulunmaktadır. İlk kez, antik yazar Hierokles tarafından bahsedilen ve günümüzde "Kale" olarak adlandırılan kent, Hellenistik Dönem'de kurulmuş ve M.S. 12. yüzyıla değin varlığını sürdürmüştür. 1984 yılında N. Mersich tarafindan Sariidris kasabasında bulunan bir yazıt ile tespit edilen kent ile Anadolu'da aynı ismi taşıyan üç kent daha bulunmaktadır [24]. Hellenistik Roma Dönemi'nden itibaren bir statüsü kazanan kent, o dönemlerde sikke de basmıştır. Orta büyüklükte bir kent olan Mallos'un akropolisinde; düzenli bir savunma ve su sistemi, üç adet kilise, bouleuterion, tapınak, üç adet nekropolis alanı ve geniş iskân alanları bulunmaktadır. Kentin agorası, akropolisin doğusunda konumlanırken agoranın hemen batısında, arkası akropolise yaslandırılmış ve ana kayaya oyularak yapılmış oturma sıraları bulunan alan açık hava toplantı alanı olarak kullanılmıştır. Agoranın karşısına D-B yönlü inşa edilmiş yapı kentteki en büyük kilisedir [25]. Mallos Antik Kenti'nde mevcut bir kazı çalışması olmamakla birlikte yüzey araştırmaları Süleyman Demirel Üniversitesi, Arkeoloji Bölümü öğretim üyesi Dr. Fikret Özcan tarafindan yürütülmektedir. 


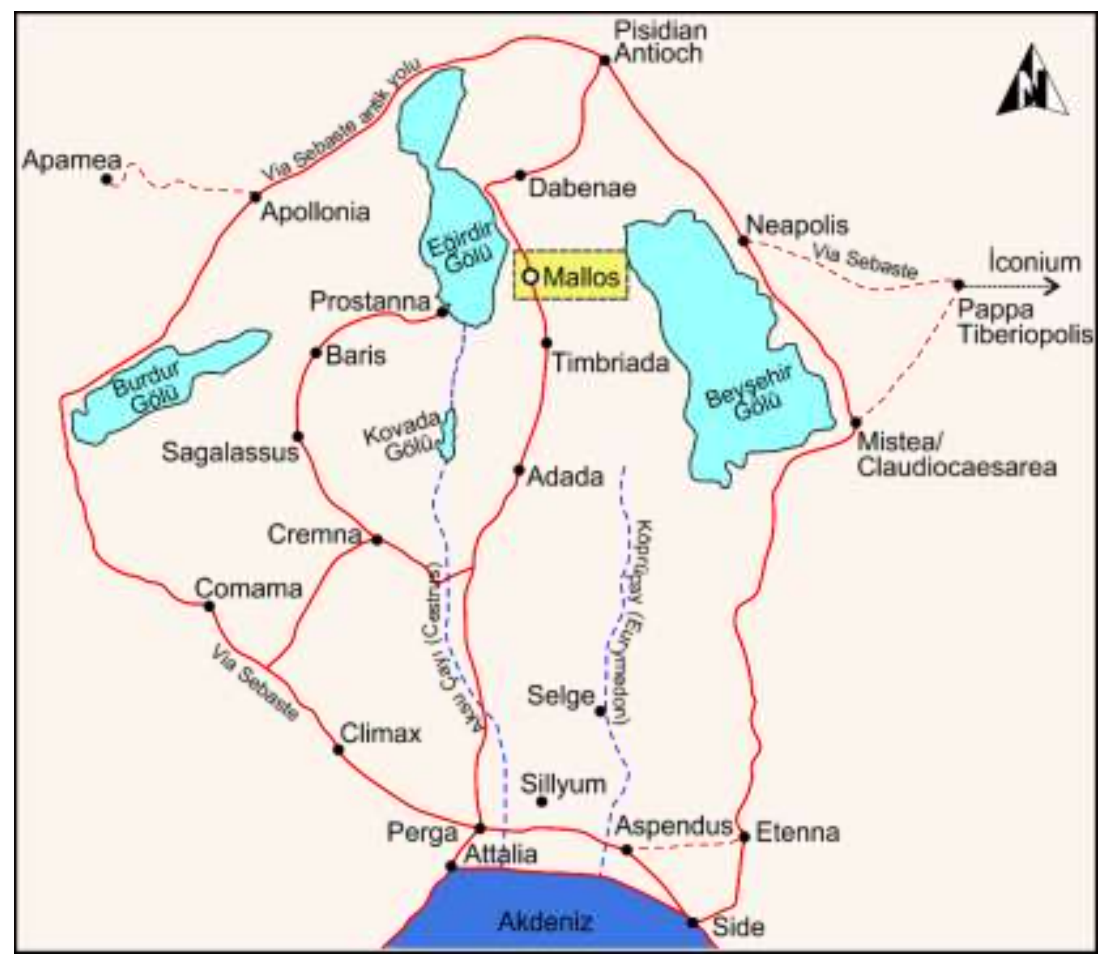

Şekil 1. Mallos Antik Kenti ve yakın çevresi ([26]'dan düzenlenmiştir)

\subsection{Yer Radarı Yöntemi}

Yer radarı, son zamanlarda arkeolojik çalışmalarda gömülü arkeolojik özellikleri, eserleri/yapıları ve yakın yüzeydeki önemli kültürel tabakaları hızlı ve doğru bir şekilde belirleyebilen bir yöntem olarak geniş bir kabul görmüştür. Özellikle, merkez anten frekansına bağlı olarak $20 \mathrm{~cm}$ ile $5 \mathrm{~m}$ derinlik seviyeleri arasında ve içinde bulunduğu ortam ile önemli fiziksel ve kimyasal zıtlığa sahip metalik ve metalik olmayan hedefleri yüksek çözünürlükle görüntüleyebilen bir yöntemdir. Bu yöntemde, yüksek frekanslı bir elektromanyetik sinyal bir verici antenden yere iletilir. Sinyal yeraltında bir tabaka sinırı veya bir nesne ile karşılaştı̆̆ında yansıyarak ya da saçılarak alıcı antene ulaşır ve varış süresinin bir fonksiyonu olarak kaydedilir (Şekil 2). Böylece, yer içinin elektrik özelliklerindeki değişimlerini temsil eden bir yeraltı görüntüsü elde edilir [27].

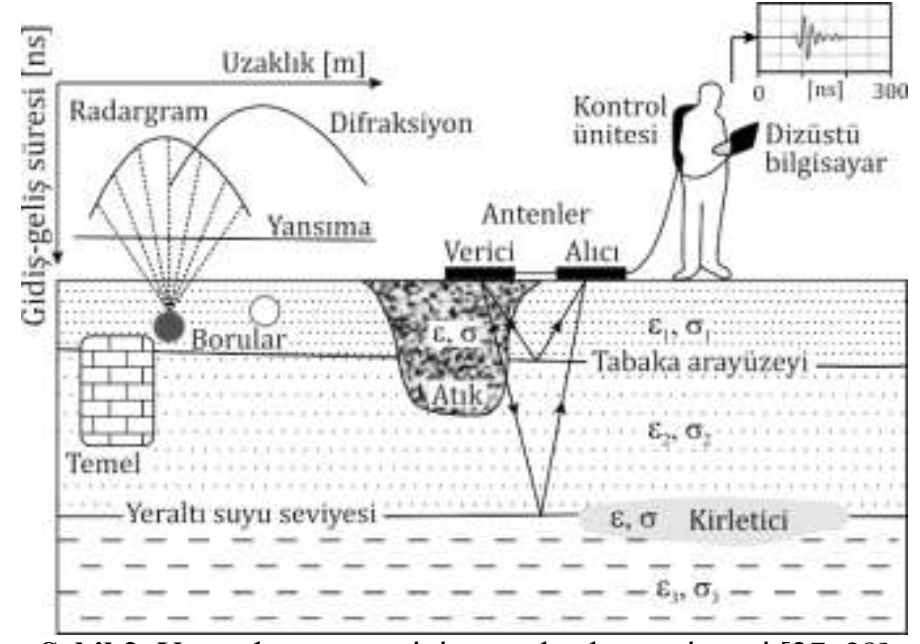

Şekil 2. Yer radarı yönteminin genel çalışma sistemi [27, 28]

Pisidia Mallos Antik Kenti'nde yer radarı çalışması, kentin agora alanında $500 \mathrm{MHz}$ merkez frekanslı kapalı bir anten sistemi kullanılarak zig-zag ölçümler şeklinde gerçekleştirilmiş ve yaklaşık DB doğrultulu 223 profil üzerinde toplam $4745 \mathrm{~m}$ uzunluğunda veri toplanmıştır. Şekil 3a, yer radarı 
çalışma alanının kentin agorası üzerindeki yaklaşık konumunu, şekil içerisindeki kırmızı oklar ise bu alanda yoğun olarak görülen kaçak kazı çukurlarından bazılarını göstermektedir. $\mathrm{Bu}$ alanda gerçekleştirilen yer radarı çalışmasının ölçüm profilleri Şekil 3b'de verilmiştir. Uygulamada, ölçüm profilleri aras $50 \mathrm{~cm}$, iz aralığ $5 \mathrm{~cm}$ ve zaman penceresi ise $80 \mathrm{~ns}$ olarak belirlenmiş, değerlendirmede ise kazanç, arka plan etkisinin giderilmesi, medyan filtre, bant geçişli süzgeç $(150-800 \mathrm{MHz})$ ve migrasyon $(0.09 \mathrm{~m} / \mathrm{ns})$ gibi temel veri işlem teknikleri uygulanmıştır [29].
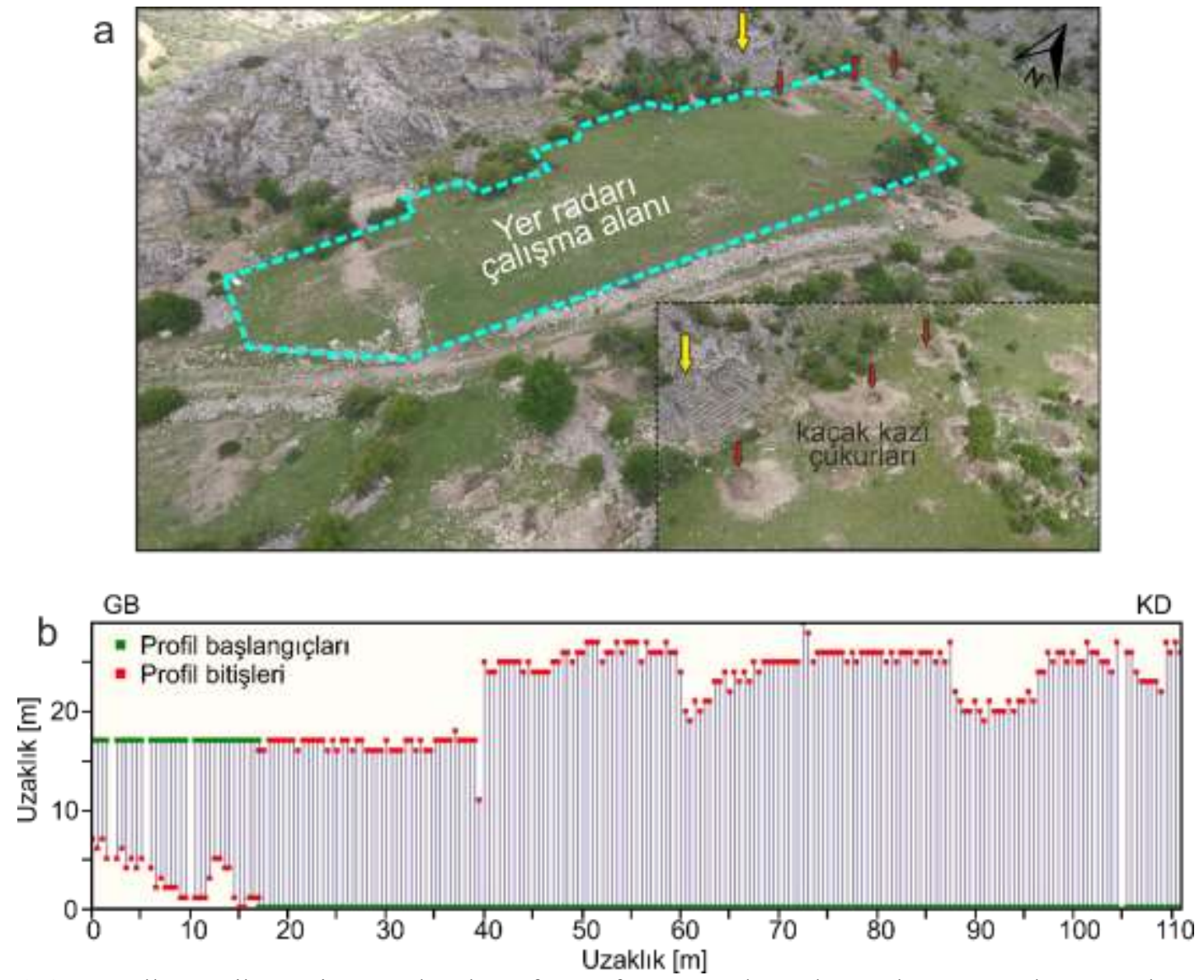

Şekil 3. a) Mallos Antik Kenti agora alanı hava fotoğrafı ve yer radarı çalışma alanının sınırları. Küçük resim merdiven basamakların önündeki kaçak kazı çukurlarını göstermektedir. b) Yer radarı çalışmasının ölçümm profilleri

\section{Bulgular ve Tartışma}

Yer radarı veri kümelerinin değerlendirilmesiyle yüzeyden $3.9 \mathrm{~m}$ derinlik seviyesine kadar kesitler elde edilmiştir. Şekil 4a-d, sırasıyla 0.2-0.4 m, 0.6-0.9 m, 1.3-1.5 m ve 1.8-2.0 m arasındaki derinlik seviyeleri için elde edilen kesitleri göstermektedir. Bu kesitler irdelendiğinde $0.2 \mathrm{~m}$ derinlik seviyesinden itibaren belirli bir geometrik forma sahip belirtilerin elde edildiği görülmektedir. $\mathrm{Bu}$ belirtiler, çalışma alanının güneybatısından itibaren 1-4 arasında rakamlarla numaralandırılmış ve Şekil 4b $(0.6-0.9 \mathrm{~m})$ ve Şekil 4c'de (1.3-1.5 m) sunulan derinlik kesitleri üzerinde siyah kesikli çizgiler arasında gösterilmiştir. Bunlar arasında 1 numara ile gösterilen ve çalışma alanının en güneyinde agoranın giriş kapısı civarında belirlenen belirti $5.4 \mathrm{~m}$ genişliğindedir. Kentin sur duvarları olduğu düşünülen ve 2, 3 rakamlarıla gösterilen belirtiler $1.5 \mathrm{~m}$ ve 4 numaralı belirti ise $11 \mathrm{~m}$ genişliğinde ilgili kesitlerde izlenmektedir. Şekil 4d'de verilen 1.8-2.0 m derinlik seviyelerine ait kesit incelendiğinde 4 numaralı ve dikdörtgen şeklinde bir yapı sunan belirtinin yaklaşık $10 \mathrm{~m} \times 10 \mathrm{~m}$ (düz yeşil çizgi) boyutlarında kare şeklinde iç tarafı boş bir yapı şeklinde izlenmeye başladığı görülmektedir.

Şekil 5a-d, sırasıyla 1.9-2.2 m, 2.1-2.3 m, 2.3-2.5 m ve 3.1-3.3 m arasındaki derinlik seviyeleri için elde edilen kesitleri göstermektedir. Bu kesitlerde kare şeklindeki yapının izlerinin giderek azaldığı görülürken ilk üç belirti izlenmeye devam etmiştir. Çalışma alanının kuzeydoğusunda, 102-110 m'ler arasında kesikli daire içinde görülen ve belirli bir geometri sunmayan bir belirti ayrıca dikkat çekicidir 
(Şekil 5a). Yüzeyden 3 m derinlik seviyelerine kadar kesitlerde izlenebilen bu belirti, Şekil 3a'da oklarla gösterilen alandaki mevcut kaçak kazı çukurlarının yoğun olduğu bölgededir. Şekil 6d'de sunulan 3.13.3 m derinlik seviye kesiti dikkate alındığında sadece 2 ve 3 numaralı sur duvarı olduğu düşünülen belirtiler izlenmektedir. Bu belirtiler, burada sunulmamakla birlikte $3.9 \mathrm{~m}$ derinlik seviyesine kadar yüksek genlik değerleriyle varlığını sürdürmektedir.
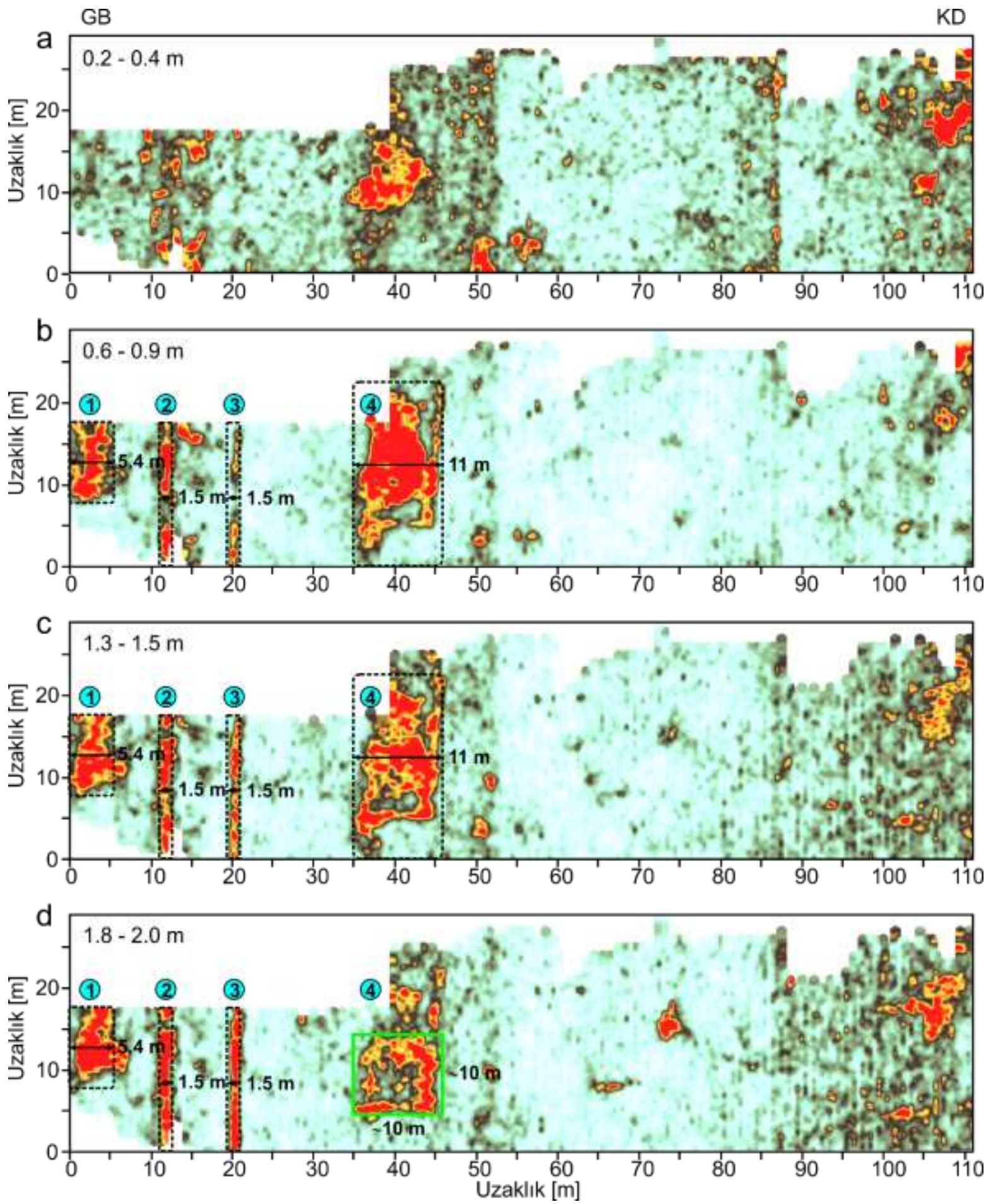

Şekil 4. Yer radarı derinlik seviye kesitleri a) $0.2-0.4 \mathrm{~m}$ b) $0.6-0.9 \mathrm{~m} \mathrm{c}$ ) $1.3-1.5 \mathrm{~m} \mathrm{~d}$ ) $1.8-2.0 \mathrm{~m}$ 

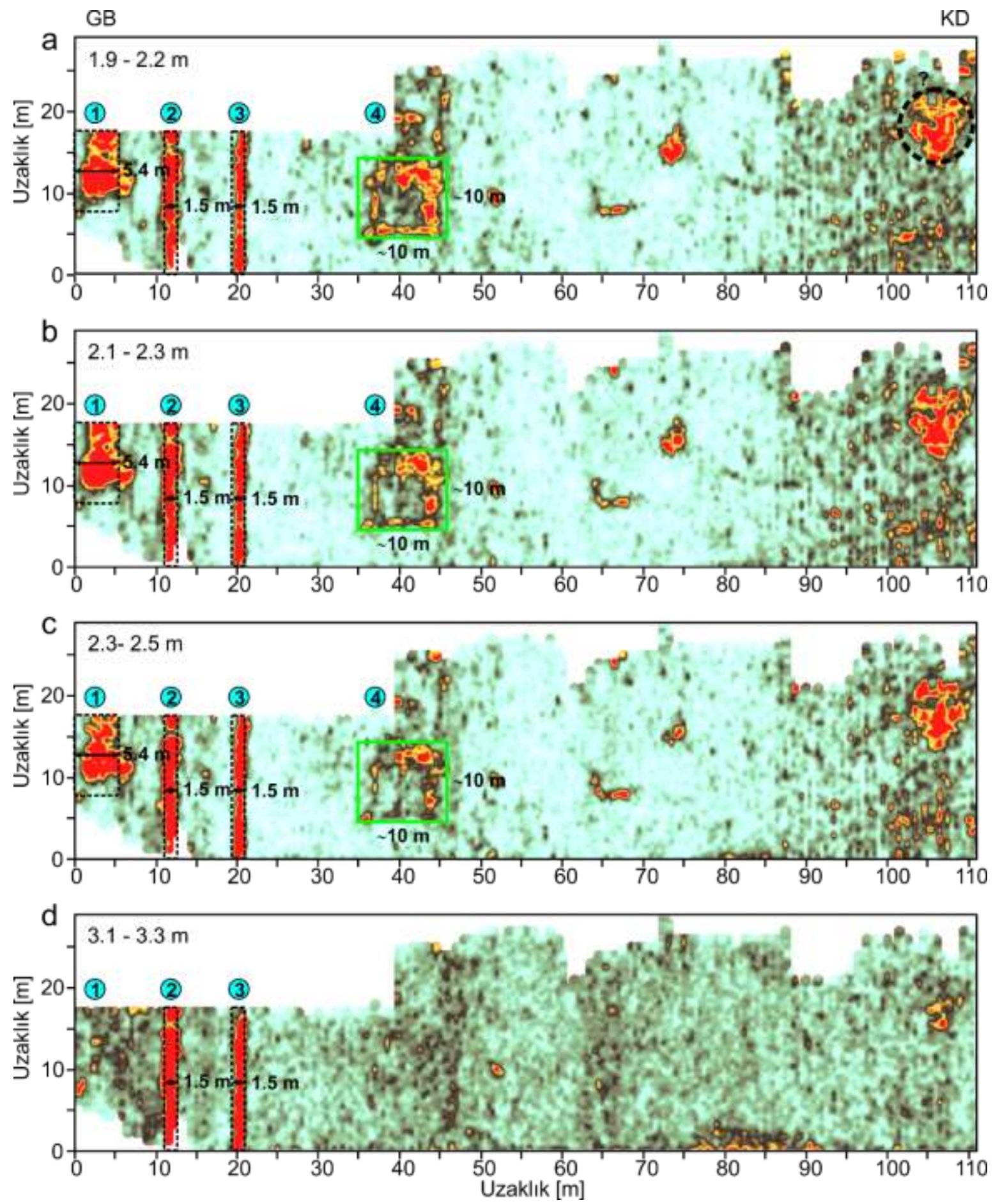

Şekil 5. Yer radarı derinlik seviye kesitleri a) 1.9-2.2 m b) 2.1-2.3 m c) 2.3-2.5 m d) 3.1-3.3 m

\section{Sonuç ve Öneriler}

Mallos Antik Kenti agora alanındaki olası yapı kalıntılarının yeri, derinliği ve uzanımlarının belirlenerek antik dokunun ortaya çıkarılması amacıyla arkeolojik alan araştırmalarında en yaygın kullanılan yöntemlerden biri olan yer radarı çalışması gerçekleştirilmiştir. Yer radarı çalışması, kentin agora alanında düzgün geometriler sunan 4 belirtinin belirlenmesini sağlamıştır. Bu belirtilerden ilki, alanın güneybatısında konumlanan agoranın giriş kapısı civarında dikdörtgen formda ve yaklaşık olarak $5.5 \mathrm{~m}$ $\times 7.5 \mathrm{~m}$ boyutlarındadır. İki ve üçüncü belirtiler, aralarında yaklaşık $8 \mathrm{~m}$ kadar bir uzaklık bulunan 1.5 $\mathrm{m}$ genişliğinde ve $17.5 \mathrm{~m}$ uzunluğunda olan yapılardır. Bu yapıların akropolü koruyan surlara ait oldukları düşünülmektedir. Mallos Antik Kenti'nde yüzey araştırması çalışmalarını sürdüren Dr. Özcan'a göre (sözlü görüşme) bu sur duvarlarından daha güneyde olan dış sur Hellenistik Dönem, iç 
sur ise kent sınırlarının daraltıldığg Geç Antik Dönem'e ait olmalıdır. Son belirti ise iç sur duvarından yaklaşı1 $15 \mathrm{~m}$ uzaklıkta ve yer radarı derinlik kesitlerinde yüzeyin $20 \mathrm{~cm}$ altından itibaren gözlemlenen $11 \mathrm{~m}$ genişliğinde dikdörtgen şekilli bir yapıdır. Bu yapı, $1.5 \mathrm{~m}$ derinliğine kadar kendini korurken bu derinlik seviyesinden sonra $\sim 10 \mathrm{~m} \times \sim 10 \mathrm{~m}$ boyutlarında iç kısmı boş kare şeklinde bir yapıya dönüşmekte ve $2.5 \mathrm{~m}$ derinlik seviyesine kadar izlenmektedir. Bu yapının, agora alanında bulunan bir işliğe (atölye) ait olduğu düşünülmektedir. İşliğin temeli $2.5 \mathrm{~m}$ olarak düşünülürse, yer radarı kesitlerinde $3.3 \mathrm{~m}$ derinlik seviyesinde bile yüksek genlik değerleriyle gözlemlenen sur duvarları yaklaşık $1.5 \mathrm{~m}$ daha derinde konumlandırılmış olmalıdır. Kentin agora alanında gerçekleştirilen yer radarı çalışmasının bu umut verici bulguları ışığında özellikle 4 numaralı belirtinin gözlemlendiği alanda bir elektrik özdirenç tomografi çalışmasının gerçekleştirilmesi önerilmektedir. Her iki çalışmadan elde edilecek bulgular bir arada değerlendirilerek kaçak kazıların oldukça yoğun gerçekleştiği bu alanda bir arkeolojik deneme açmasının gerçekleştirilmesi uygun olacaktır. Mallos Antik Kenti'nde yürütülen arkeolojik çalışmaların yüzey araştırmaları olarak devam ettiği düşünüldügünnde elde edilen/edilecek sonuçlar ileri dönemlerdeki kazı planlaması çalışmalarına rehberlik edecektir.

\section{Teşekkür}

Görüş ve eleştirileriyle bu çalışmanın gelişmesine katkı sağlayan Dr. Aydın BÜYÜKSARAÇ'a teşekkür ederiz. FYL-2019-6976 no'lu proje kapsamında bu çalışmayı maddi olarak destekleyen Süleyman Demirel Üniversitesi (SDÜ) Bilimsel Araştırma Projeleri (BAP) Yönetim Birimi Başkanlığı'na ve alan uygulamasında cihaz ve ekipman desteği sağlayan SDÜ Deprem ve Jeoteknik Araştırma Merkezi'ne teşekkür ederiz.

\section{Yazarların Katkısı}

Çağlayan BALKAYA makalenin yazım ve bilimsel gelişim, Açelya SEVER şekillerin sunumu, Olcay ÇAKMAK veri toplama/değerlendirme ve Fikret ÖZCAN yorum aşamalarında katkıda bulunmuştur.

\section{Çıkar Çatışması Beyanı}

Yazarlar tarafından herhangi bir çıkar çatışması beyan edilmemiştir.

\section{Araştırma ve Yayın Etiği Beyanı}

Yapılan çalışmada araştırma ve yayın etiğine uyulmuştur.

\section{Kaynaklar}

[1] Belshé J.C. 1957. Recent Magnetic Investigations at Cambridge University. Advances in Physics, 6 (22): 192-193.

[2] Aitken M.J. 1958. Magnetic Prospecting I. Archaeometry, 1 (1): 16-20.

[3] Fassbinder J.W.E. 2017. Magnetometry for Archaeology, in Encyclopedia of Geoarchaeology. Edited by Gilbert A.S., Encyclopedia of Earth Sciences Series, Springer, Dordrecht, 499-514.

[4] De Terra H. 1947. A Preliminary Note on the Discovery of Fossil Man at Tepexpan in the Valley of Mexico. American Antiquity, 13: 40-44.

[5] Bevan B., Kenyon J. 1975. Ground-Penetrating Radar for Historical Archaeology. MASCA Newsletter, 11 (2): 2-7.

[6] Vickers R.S., Dolphin L.T. 1975. A Communication on an Archaeological Radar Experiment at Chaco Canyon, New Mexico. MASCA Newsletter, 11 (1): 6-8.

[7] Conyers L.B. 2006. Ground-penetrating radar, in Remote Sensing in Achaeology: an Explicitly North American Perspective. Edited by Johnson J.K., The University of Alabama Press, Tuscaloosa, AL., 131-159.

[8] Yaramancı A. 1970. Keban Projesi Jeofizik Araştırmaları Ön Raporu, 1968 Yaz Çalışmaları. ODTÜ Keban Projesi Yayınları, Türk Tarih Kurumu Basımevi, Ankara, 1 (1): 13-19. 
[9] Kaya M.A., Balkaya Ç., Ekinci Y.L., Demirci A. 2013. Kültür Mirasımız, Torunlarımızın Emaneti için Arkeojeofizik Neden, Nereye? Jeofizik Bülteni, 72: 29-45.

[10] Drahor M.G. 2006. Integrated Geophysical Studies in the Upper part of Sardis Archaeological Site, Turkey. Journal of Applied Geophysics, 59 (3): 205-223.

[11] Drahor M.G., Kurtulmuş T.Ö., Berge M.A., Hartmann M., Speidel M.A. 2008. Magnetic Imaging and Electrical Resistivity Tomography Studies in a Roman Military Installation found in Satala Archaeological Site, Northeastern Anatolia, Turkey. Journal of Archaeological Science, 35 (2): 259-271.

[12] Drahor M.G., Berge M.A., Kurtulmuş T.Ö., Hartmann M., Speidel M.A. 2008. Magnetic and Electrical Resistivity Tomography Investigations in a Roman Legionary Camp Site (Legio IV Scythica) in Zeugma, Southeastern Anatolia, Turkey. Archaeological Prospection, 15 (3): 159186.

[13] Berge M.A., Drahor M.G. 2011. Electrical Resistivity Tomography Investigations of Multi Layered Archaeological Settlements: Part I - Modelling. Archaeological Prospection, 18 (3): 159171.

[14] Berge M.A., Drahor M.G. 2011. Electrical Resistivity Tomography Investigations of MultiLayered Archaeological Settlements: Part II - A Case from Old Smyrna Höyük, Turkey. Archaeological Prospection, 18 (4): 291-302.

[15] Ekinci Y.L., Kaya M.A. 2007. 3D Resistivity Imaging of Buried Tombs at the Parion Necropolis (NW Turkey). Journal of the Balkan Geophysical Society, 10 (2): 1-8.

[16] Ekinci Y.L., Kaya M.A., Başaran C., Kasapoğlu H., Demirci A., Durgut C. 2012. Geophysical Imaging Survey in the South Necropolis at the Ancient City of Parion (Kemer-Biga), Northwestern Anatolia, Turkey: Preliminary Results. Mediterranean Archaeology and Archaeometry, 12 (2): 145-157.

[17] Arısoy M.Ö., Koçak Ö., Büyüksaraç A., Bilim F. 2007. Images of Buried Graves in Bayat, Afyon (Turkey) from High-resolution Magnetic Data and Their Comparison with Preliminary Excavations. Journal of Archaeological Science, 34 (9): 1473-1484.

[18] Büyüksaraç A., Arısoy M.Ö., Bektaş Ö., Koçak Ö., Çay T. 2008. Determination of Grave Locations in Dedemezari Necropolis (Western Turkey) using Magnetic Field Derivatives. Archaeological Prospection, 15 (4): 267-283.

[19] Ekinci Y.L., Balkaya Ç., Şeren A., Kaya M.A., Lightfoot C. 2014. Geomagnetic and Geoelectrical Prospection for Buried Archaeological Remains on the Upper City of Amorium, a Byzantine City in Midwestern Anatolia, Turkey. Journal of Geophysics and Engineering, 11 (1): 015012.

[20] Balkaya Ç., Kalyoncuoğlu Ü.Y., Özhanlı M., Merter G., Çakmak O., Güven İ.T. 2018. Groundpenetrating Radar and Electrical Resistivity Tomography Studies in the Biblical Pisidian Antioch City, SW Anatolia. Archaeological Prospection, 25 (4): 285-300.

[21] Akca İ., Balkaya Ç., Pülz A., Alanyalı H.S., Kaya M.A. 2019. Integrated Geophysical Investigations to Reconstruct the Archaeological Features in the Episcopal District of Side (Antalya, Southern Turkey). Journal of Applied Geophysics, 163: 22-30.

[22] Yilmaz, S., Balkaya Ç., Çakmak O., Oksum E. 2019. GPR and ERT Explorations at the Archaeological Site of Kılıç Village (Isparta, SW Turkey). Journal of Applied Geophysics, 170: 103859.

[23] Kaya M.A, Özyalın Ş. 1999. Malos Antik Kentinin Manyetik Yöntemle Araştırılması. Workshop: Arkeoloji ve Jeofizik, İzmir.

[24] Türkiye Arkeolojik $\quad$ Yerleşmeleri 1993. http://www.tayproject.org/TAYages.fm\$Retrieve?CagNo=5758\&html=ages_detail_e.html\&lay out=web (Erişim Tarihi: 25.09.2019).

[25] Özcan F. 2019. Mallos Antik Kenti, Antik Dönemden Günümüze Isparta'nın Kültürel Mirası. Eds. Hürmüzlü B., Köker H., Mörel A., Desen Ofset A.Ş., Ankara, 128-131.

[26] Wilson M. 2009. The Route of Paul's First Journey to Pisidian Antioch. New Testament Studies, 55 (4): 471-483.

[27] Balkaya Ç., Göktürkler G. 2016. Karş11ıklı Kuyu Yer Radarı Verilerinin Modellenmesi. Pamukkale Üniversitesi Mühendislik Bilimleri Dergisi, 22 (6): 581-596. 
[28] Blindow N., Eisenburger D., Illich B., Petzold H., Richter T. 2007. Ground Penetrating Radar. in Environmental Geology - Handbook of Field Methods and Case Studies, Edited by Knödel K., Lange G., Voigt H-J., Springer Berlin Heidelberg, New York, 283-336.

[29] GPR-SLICE v7.0. Ground-penetrating Radar Imaging Software. https://www.gpr-survey.com/ (Erişim Tarihi: 01.09.2019). 